\title{
Consideration of Congenital Hypothyroidism as the Possible Cause of Autism
}

\author{
Xiaobin $\mathrm{Xu}^{1}$, Hirohiko Kanai ${ }^{2}$, Masanori Ookubo ${ }^{3}$, \\ Satoru Suzuki ${ }^{4}$, Nobumasa Kato ${ }^{5}$ and Miyuki Sadamatsu ${ }^{6}$ \\ ${ }^{1}$ Center For Neuropsychiatric Disorders, Institute \\ of Life Science, Nanchang University 330031, \\ ${ }^{2}$ Dept. Psychiatry, Shiga Univ. Med. Sci., Shiga, \\ ${ }^{3}$ Dept. Psychiatry, Minakuchi Hosp., Koka City, Shiga, \\ ${ }^{4}$ Dept. Aging Med. and Geriatrics, Shinshu Univ., Nagano, \\ ${ }^{5}$ Dept. of Psychiatry, Karasuyama Hospital, Showa Univ. Sch.of Med., Tokyo, \\ ${ }^{6}$ Dept. Psychiatry, Nara Med. Univ. Nara, \\ ${ }^{1}$ China \\ 2,3,4,5,6 Japan
}

\section{Introduction}

Autism is a behaviorally defined disorder associated with characteristic impairments in social interactions and communication, as well as restricted and repetitive behaviors and interest. Its prevalence was thought to be 2 in 10,000, but recently, several large reviews on autism prevalence revealed that the rate of occurrence is approximately 30 in 10,000. While autism has been considered a developmental disorder, little is known about its causes.

The genetic component clearly plays an important role in the pathophysiology of this disorder. However, environmental factors can also cause developmental disabilities. Case reports of autism associated with environmental factors, such as rubella virus, valproic acid, and thalidomide exposure during pregnancy, led to the hypothesis that nongenetic mechanisms may also produce an autistic syndrome (Chess 1977).

Thyroid hormone is essential for brain development and maintenance of basal metabolic rates. Manipulation of the thyroid hormone in laboratory animals typically increases activity levels and decreases performance during motivated learning tasks. It is well known that hypothyroidism during the critical period of brain development induces irreversible dysfunction of the central nervous system (CNS). The timing of thyroid hormone manipulation plays a critical role in the degree to which developmental sequelae are expressed. Lactating rats receiving $0.02 \%$ propylthiouracil (PTU) in their drinking water transfer the goitrogenic effect to the offspring through their milk. This treatment induces a temporary mild hypothyroid condition in the pups (Van Middlesworth 1980). We conducted experiments to investigate the effects of temporary neonatal PTU-induced hypothyroidism on behavior of rats. Rat pups were treated with $0.02 \%$ PTU in drinking 
water which was given to dams from day 0 through day 19 post partum (Kato 1982). The serum T4 level was depressed below the limit of detection at 2 weeks of age, but recovered to the normal level at 4 weeks of age (Akaike 1991). The open field test was conducted at 3 , 6 , and 9 weeks of age. At 3 weeks of age, the number of ambulations did not differ between PTU-treated rats and controls. At 6 and 9 weeks of age, the number of ambulations of PTUtreated rats was significantly higher than that of control rats. Kato et al. reported extensive hyperactivity (Akaike 1991; Akaike 1997) and attenuated habituation in the open field test in PTU-treated rats after maturation, as shown in Fig 1 (Kato 1992).

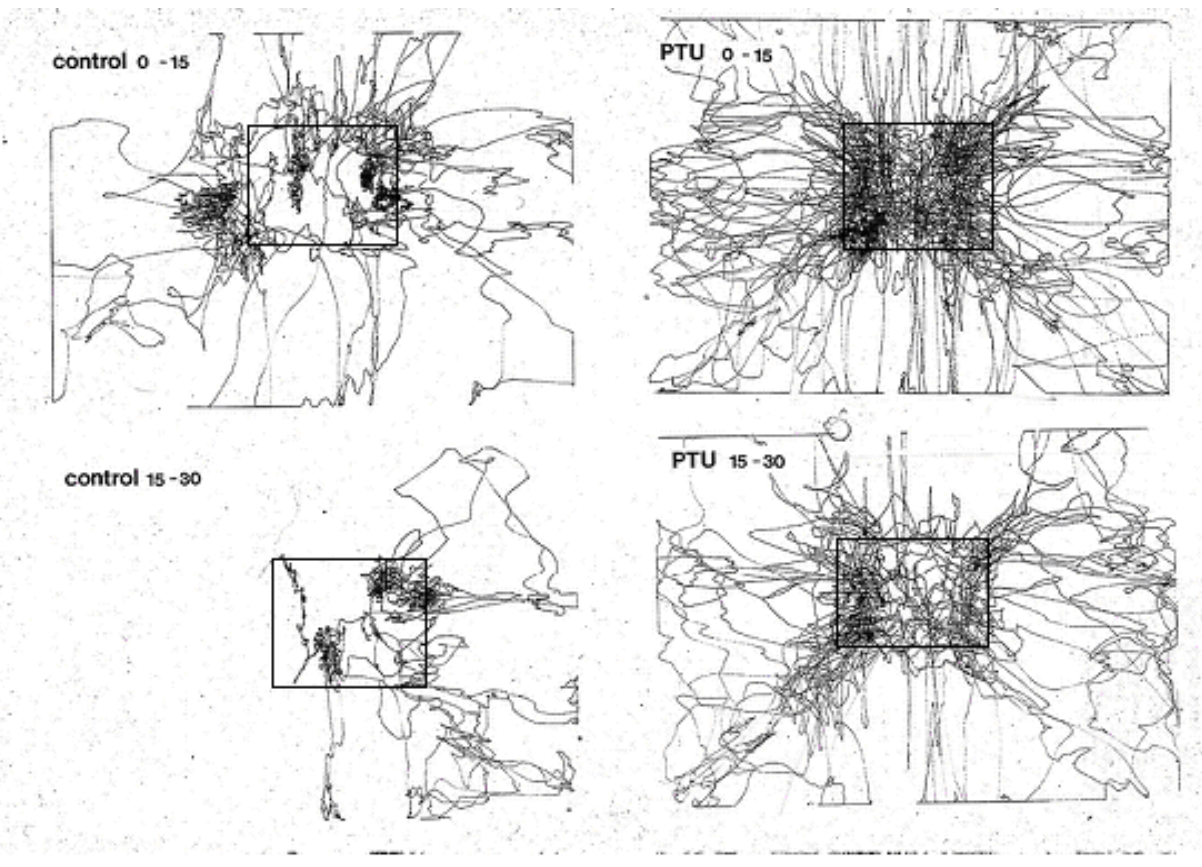

Fig. 1. Comparison of spontaneous movement in a propylthiouracil (PTU)-treated rat (right) and its littermate control (left), as detected by a multidimensional behavioral analyzer (Animex II) at the age of 10 weeks. The device recorded the linear locomotion activity of the animal for 2 consecutive 15-min periods. The rectangle in the centre of each figure indicates the base of the cage and traces outside the rectangle indicate rearing (Kato 1992).

The functions of thyroid hormones in brain are mediated by 2 isoforms of thyroid hormone receptors (TRs), TR- $\alpha$ and TR- $\beta$ (Leonard JL 1994). TR- $\alpha$ and TR- $\beta$ are expressed in a cell- and region-specific manner and differentially control a wide array of gene expression throughout the prenatal and postnatal periods (Mellström B 1991; Bradley 1992). While TR-a expression is widely distributed during the prenatal period, the distribution of TR- $\beta$ expression is more restricted and almost overlaps with that of TR-a before birth; however, TR- $\beta$ expression is more widely distributed and increases after birth(Mellström B 1991; Bradley 1992).

In the rodent brain, the striatum and hippocampus, 2 important regions in the limbic system, have the highest expression of both TRs throughout the prenatal and neonatal 
period, and high TR expression levels are maintained into adulthood (Bradley 1992). Because developmental program and function acquisition are strictly controlled, it has been hypothesized that lack of TR-signaling in the critical period causes permanent functional abnormalities related to TR-expressing regions (Manzano J 2007). Dramatic cytoarchitectural maturation seems to occur 2-3 weeks after birth in the normal caudate. Neonatal hypothyroidism in a PTU model causes a marked maturational delay in caudate neuronal proliferation, elaboration of neuronal networks, and attainment of mature synaptic contacts in rat pups (Lu EJ 1977). However, the internal supply of thyroid hormones after the lactating period results in a rapid "catch-up" phenomenon of caudate synaptogenesis (Lu EJ 1977). Repression of thyroid function does not entirely prevent development of the caudate nucleus, but it allows a fairly extensive, though critically incomplete, degree of maturation. Similarly, neonatal thyroid hormone deficiency has been reported to interfere with the contact between mossy fibers and dendritic excrescences of CA3 pyramidal cells of the rat hippocampus (Madeira MD 1993). Although the change in the total number of synapse enabled a complete "catch-up," synaptic reorganization was not fully achieved, as revealed by the reduction in the size of the synaptic sites (Madeira MD 1993). However, the critical mechanisms, as well as the role of TR signaling, remain unclear in such permanent behavioral abnormalities.
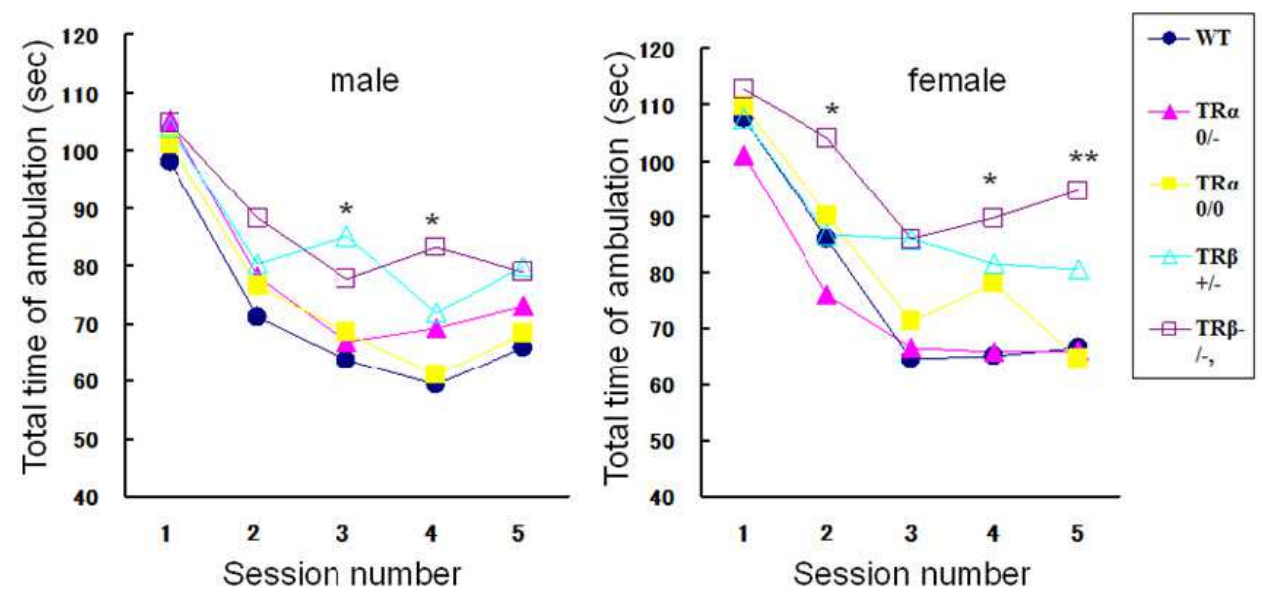

Fig. 2. The locomotor activity in male and female thyroid hormone receptor (TR)-mutant mice. Whereas the wild-type mice habituated over multiple sessions, TR- $\beta^{+/-}$mice and TR- $\beta /-$ mice exhibited significant hyperactivity. Gender difference is not statistically significant. (ANOVA, ${ }^{*} \mathrm{p}<0.01,{ }^{* *} \mathrm{p}<0.001$ ).

TRs bind to thyroid hormone response elements in the promoter region and regulate a wide array of genes (Zhang J 2000; Jeyakumar M 2007). N-CoR (nuclear receptor corepressor), SMRT (silencing mediator of retinoid and thyroid hormone receptors), and histone deacetylase 3 form large complexes with unliganded TRs, and these complexes mediate the basal transcriptional regulation both positively and negatively. In the presence of T3, corepressor complexes are released from liganded TRs that, in turn, associate with 
coactivator complexes containing SRC (steroid receptor coactivators), CBP (cAMP response element-binding protein-binding protein), and P/CAF (Zhang J 2000; Jeyakumar M 2007). Thus, gene regulation mediated by TRs involves histone modification, and therefore, raises the possibility that TR-gene disruption induces chronic epigenetic changes in the TR-related brain regions.

Genetic disruption of TRs causes distinct behavioral impairments in humans and in animal models. TR- $\beta$ knock-in mice (TR- $\beta^{\text {PV }}$ mice) show hyperactivity with lack of habituation, which is similar to findings observed in a PTU-treated model (Wong R 1997; Siesser WB 2005; Siesser WB 2006). Methylphenidate is a psychostimulant drug approved for treatment of attention deficit hyperactivity disorder (ADHD), and is known to paradoxically decrease hyperactivity in ADHD children. This drug is effective in reducing hyperactivity of TR- $\beta^{\mathrm{PV}}$ mice as well (Wong R 1997). In contrast, TR-a mutant mice were reported to show memory impairment and an increased anxiety profile (Wallis K 2008). In humans, an inherited syndrome caused by the mutated TR- $\beta$ gene, resistance to thyroid hormone (RTH), has been described, whereas lack of TR-a is thought to be lethal. Most patients with RTH are heterozygous, carrying only 1 mutated gene. A generalized form of RTH is characterized by reduced responsiveness of the pituitary and peripheral tissues to thyroid hormones and has a high ratio of comorbid ADHD which reaches up to 40-70\% (Siesser WB 2005). Although disruption of TR signaling is transient in a PTU-treated model, disruption of the TR- $\beta$ gene appears to cause common behavioral abnormalities. In addition to its important roles in behavior, various alterations of the monoaminergic systems have been reported either in TR-gene disrupted animal models or in a PTU-treated model. To investigate the roles of TRsignaling in behavioral changes, we performed behavioral tests in TR-gene disrupted mice. In addition, we determined dopamine and serotonin concentrations in the striatum and hippocampus of male TRs mutant mice by using high performance liquid chromatography. We measured the striatal and hippocampal expressions of proteins, including acetylated histone H3, an epigenetic marker, and glial fibrillary acidic protein (GFAP), a marker of proliferation and maturation of astrocytes.

We used the following 5 strains ( $\mathrm{N}=5$ or 6 each): TR-a ${ }^{0 / 0}$, TR-a $0 /-$, TR- $\beta^{+/-}$, TR- $\beta-/$, and wildtype mice (Forrest D 1996; Gauthier K 2001). In addition to learning impairments, the characteristic behavioral abnormality in a PTU-treated model is hyperactivity. We used an open field test to compare locomotor activities in each mouse strain of both genders (Fig 1). As results of the open field tests, TR-a ${ }^{0 / 0}$ mice did not show any apparent difference compared to wild-type mice with regard to total time of ambulation and other indicators, eg, number of rearing. TR-a ${ }^{0 / 0}$ mice exhibited a slightly increased tendency of mean latency to enter novel areas compared with that of wild-type mice (data not shown). In contrast, TR$\beta^{+/-}$mice and TR- $\beta$-/- mice exhibited significant hyperactivity. Since TR- $\beta^{\text {PV }}$ mice have been reported to exhibit hyperactivity, our results were likely to confirm the relationship between hyperactivity and TR- $\beta$ gene in another mutant mouse strain. Dopamine concentrations were significantly increased in the striatum and slightly, but not statistically significant, increased in the hippocampus of TR- $\beta^{+/-}$mice and TR- $\beta^{-/-}$mice (Fig 3). Serotonin concentrations in the striatum and hippocampus did not differ among all strains (data not shown). As results of western blotting analysis, acetylation of histone $\mathrm{H} 3$ in the striatum was significantly increased in TR- $\beta^{+/-}$mice and slightly increased in TR- $\beta /-$ mice, suggesting the possibility of epigenetic changes in gene expression (Fig 4). These findings emphasize the 
possibility of a functional alteration of the dopaminergic system in the striatum. In the hippocampus, there was no change in the concentrations of dopamine and serotonin among the strains, but elevated GFAP expression was noted in TR-a ${ }^{0 / 0}$ and TR-a $\mathrm{a}^{0 /-}$ mice, indicating the possible involvement of minimal neuronal loss and reactive gliosis there (Fig 4). Both T3 and T4 can be transported into the CNS, and T4 can be converted to bioactive T3 and subsequently metabolized mainly in astrocytes (Leonard JL 1994; Guadaño-Ferraz A 1997). In addition specific neuronal loss, the activation and/or proliferation of astrocytes per se might indirectly contribute to changes in hippocampal TR signaling.

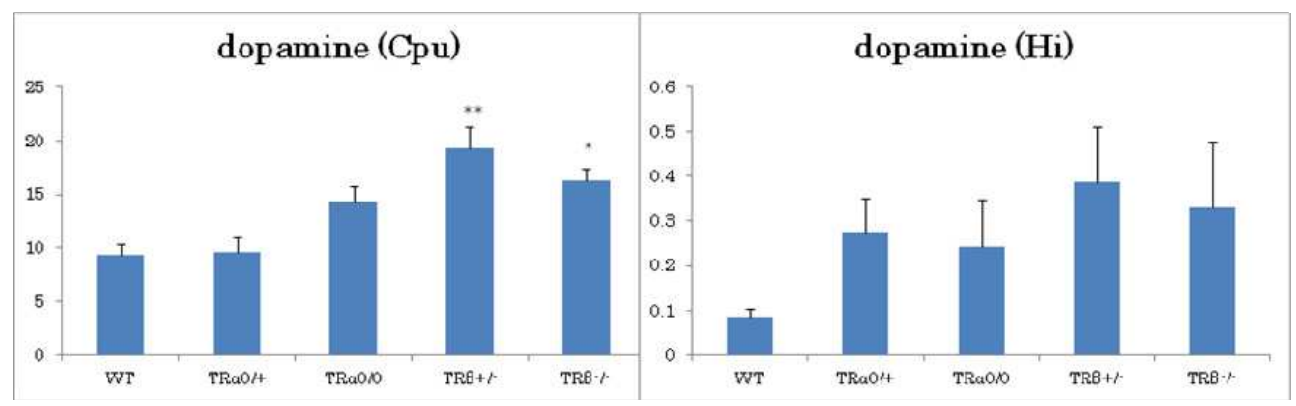

Fig. 3. Dopamine concentrations in the striatum (Cpu) and hippocampus (Hi) of thyroid hormone receptor (TR)-mutant mice. Dopamine concentrations in TR- $\beta^{+/--}$and TR- $\beta-/-$ mutant mice were significantly elevated in the striatum, but not in the hippocampus. $\left({ }^{*} \mathrm{p}<0.01,{ }^{* *} \mathrm{p}<0.001\right)$

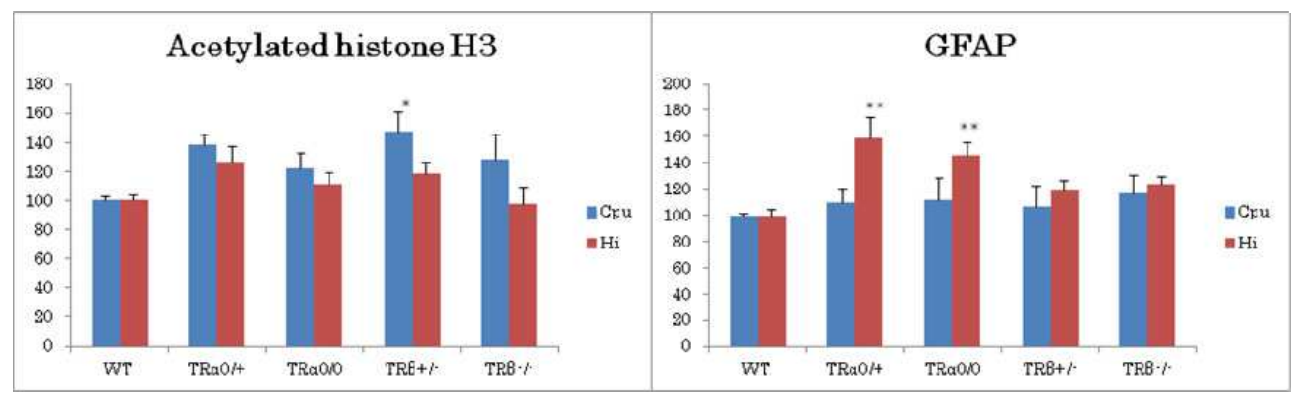

Histone modification and glial marker expression in the striatum and hippocampus.

A cetylation of histone $\mathrm{H} 3$ was significantly increased in the striatum of TR- $\beta^{+/-}$mice. GFAP expressions were significantly elevated in the hippocampus of TR- $\mathrm{a}^{0 / 0}$ and TR- $\mathrm{a}^{0 /-}$ mice. $\left({ }^{*} \mathrm{p}<0.01,{ }^{* *} \mathrm{p}<0.001\right)$

Fig. 4. Serum free thyroxine (T4) levels after bisphenol A (BPA) exposure

(A) Serum free T4 of dams. (B) Serum free T4 of pups.

Thyroid hormones are known to modulate a number of neurotransmitter systems, including monoamines (Ahmed OM 2010; Tousson E 2011). Genetic studies imply that variants of both dopamine and serotonin systems may frequently occur in ADHD for neurotransmitter uptake, synthesis, and breakdown functions. The prefrontal cortex, hippocampus, and striatum are strongly involved in executive functions such as planning and novelty-related decision making, as well as in the reward system (Rinaldi A 2010). These regions are densely 
innervated by serotonergic afferents from the raphe complex and dopaminergic afferents from the substantia nigra and the ventral tegmental area. Learning and memory are robustly modulated by serotonin and dopamine neurotransmitter activity at the synaptic level, and in some cases, they interact interdependently to sustain the psychobiological organization of these cognitive processes (González-Burgos I 2008). In fact, several experimental models of neurotransmitter activity, including a PTU-treated model, have identified a close association between serotonin-dopamine imbalance and cytoarchitectonic changes underlying learning and memory impairment (González-Burgos I 2008).

Recent research has demonstrated that epigenetic mechanisms, which regulate gene activity without altering the DNA code, have long-lasting effects within mature neurons (Colvis CM 2005; Tsankova N 2007). The existence of sustained epigenetic mechanisms of gene regulation in neurons has been implicated in the regulation of complex behavior, including abnormalities in mental disorders (eg, autism and ADHD) (Colvis CM 2005; Tsankova N 2007). Recently, Tousson et al. (Tousson E 2011) demonstrated that coadministration of folate ameliorated monoamine concentration changes in a PTUtreated model. Since folate participates in the enzymatic demethylation of histones, this micronutrient could play a role in the epigenetic control of gene expression. Lakshmy et al. have reported that histone acetylation sustained during the neonatal period in the whole brain of PTU-treated rats (Lakshmy R 1999). Although TRs interact histone protein complexes, the local changes of histone acetylation within regions that highly express TRs have remained unclear. In this study, we found the striatum as a region with specific increase in histone acetylation in TR- $\beta^{+/--}$mutant mice. In addition, we demonstrated increased dopaminergic contents and unchanged serotonin contents in the same region of TR- $\beta$-mutant mice. Although these results imply the possibility of a relationship between the increase in histone acetylation and the change in serotonin-dopamine balance in the striatum, further studies should be aimed at elucidating more close relationships between histone modifications and outcomes either in monoaminergic systems or in distinct hyperactivity, caused by TR- $\beta$ gene disruption.

As many publications demonstrated that a large number of toxic chemicals might affect human health, the thyroid gland and hormones secreted by it are targets of environmental contaminants as well. Beginning in the early 1960s, the mink industry, which had been prospering around the Great Lakes, began to falter-not because the demand for mink was decreasing but because of mysterious reproductive problems. Dr. Jacobson and his wife reported that the children of women who had regularly eaten Great Lakes fish polluted by poly chlorinated biphenyl (PCB), a family of synthetic chemicals used to insulate electrical equipment, showed abnormalities in cognitive and behavioral development such as visual recognition memory and short-term memory (Jacobson 1985; Jacobson JL 1991), which tend to predict later IQ. It is reported that PCBs impair the normal thyroid function, which plays a key role in brain development; thus, a delay in neurological development may be caused by perinatal exposure to PCBs (Porterfield 2000). Of course, there are other endocrinedisrupting chemicals which have also been shown to disrupt the normal thyroid function, eg, dioxins (Sher ES 1998). Some experts stated that these contaminants "contribute to learning disabilities, including ADHD and perhaps other neurological abnormalities" (Colborn 2004). 
Our research team focused on another synthetic chemical, bisphenol A (BPA), because it is widely used in the manufacture of dental sealants, linings of metal cans for preserved foods, and items such as baby bottles and the clear plastic cages to house laboratory animals. In rats, perinatal exposure to BPA has been implicated in abnormal brain development, characterized by hyperactivity and impaired cognition, even at or below the tolerable daily intake (TDI, http://www.bisphenol-a.org/health/exposure/consumer/research.html, 50 $\mu \mathrm{g} \mathrm{kg-1}$ day $^{-1}$ in humans) (Kubo 2001; Carr R 2003). While BPA is known to have mixed estrogen agonist/antagonist properties, several studies have shown that the thyroid function can be impaired by BPA. In an in vitro study, Moriyama et al. demonstrated that BPA binds to TRs and disrupts thyroid action (Moriyama 2002), while an in vivo study conducted by Zoeller et al. showed that BPA increases serum thyroxine levels and alters the expression of its responsive gene $\mathrm{RC} 3$ /neurogranin in the developing rat brain (Zoeller 2005).

We housed female Sprague-Dawley rats individually in metal cages from gestation day 7, and provided water in glass bottles. BPA was administered to these rats by dissolving it in drinking water at both doses of 0.1 and $50 \mathrm{mg} / \mathrm{L}$ from gestation day 11 to postnatal day 21 . From day 21 after birth, the offspring were housed by sex and randomly selected for T4 measurement, behavioral tests, and real time polymerase chain reaction (PCR) analysis.

T4 levels in the whole blood of dams and pups were monitored. Interestingly, low-dose BPA treatment $(0.1 \mathrm{mg} / \mathrm{L})$ reduced serum T4 levels in the dams in the first week after delivery, whereas high-dose BPA treatment $(50 \mathrm{mg} / \mathrm{L})$ showed no effect on serum T4 levels in the dams at all days tested. Maternal BPA exposure of different doses caused different changes in male pups; however, no changes were seen in female pups. Low-dose BPA exposure significantly increased serum T4 levels in male pups at day 7 after birth, while high-dose BPA exposure decreased T4 levels in male pups at day 21 after birth (Fig 5). As a positive

A

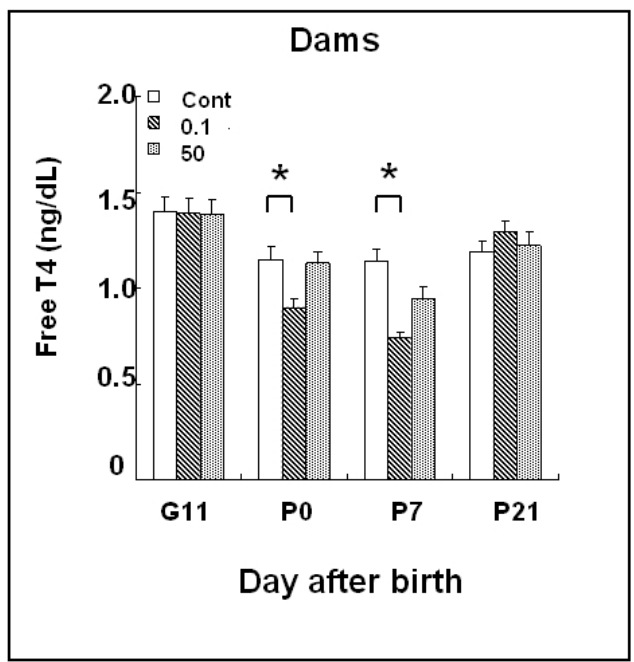

B

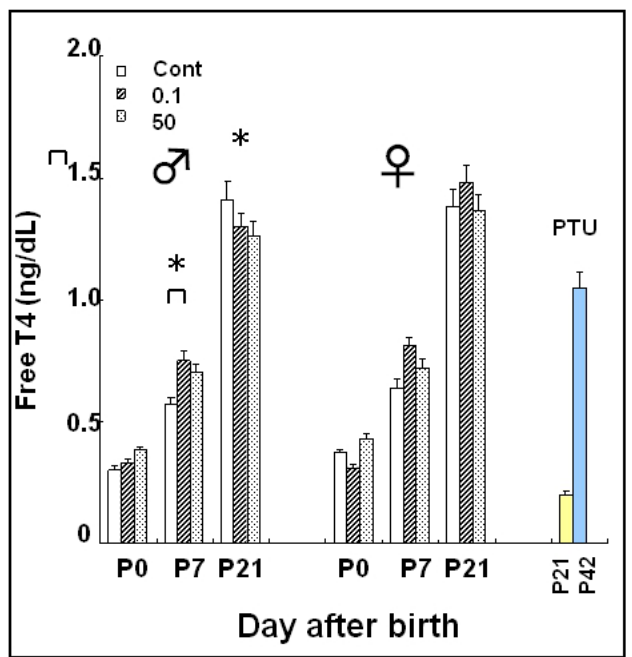

Fig. 5. Locomotor activity (left) and rearing activity (right) in the open field test. 
control, we used pups perinatally treated with $0.02 \%$ PTU through their mother's milk and their T4 values are shown in Fig 1. A severe decrease in T4 levels was induced by PTU treatment at day 21 after birth, while the value was almost that of the controls at day 42 .

With regard to the transient hyperthyroidism of pups at day 7 after birth, one can hypothesize that the thyroid gland of male pups initially compensates against the hypothyroid effect of maternal BPA, resulting in transient hyperthyroidism, and, thereafter, succumbs to the toxic effect of BPA following sustained treatment with BPA through the mother's milk.

The open field test was performed in 6-week-old pups. The open field apparatus was a round field with a $0.8-\mathrm{m}$ diameter and its bottom was divided by lines into 25 regions. To avoid confounding effects due to time differences, the test was performed from 1:00 pm to 4:00 pm every day. Each rat was placed in the central region and allowed to move freely for $3 \mathrm{~min}$. Movement from one region to another was counted as 1 ambulation, and 1 rearing was defined as the rat standing on its hind legs with both front feet were off the ground. The total numbers of ambulation and rearing were manually recorded to evaluate locomotor activity and exploratory behavior, respectively. The open field was cleaned between each subject to prevent olfactory cues from affecting the behavior of subsequently tested rats.

\section{A}

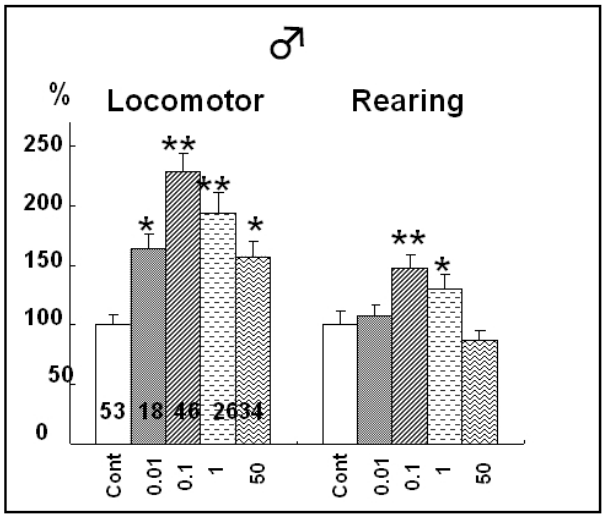

B

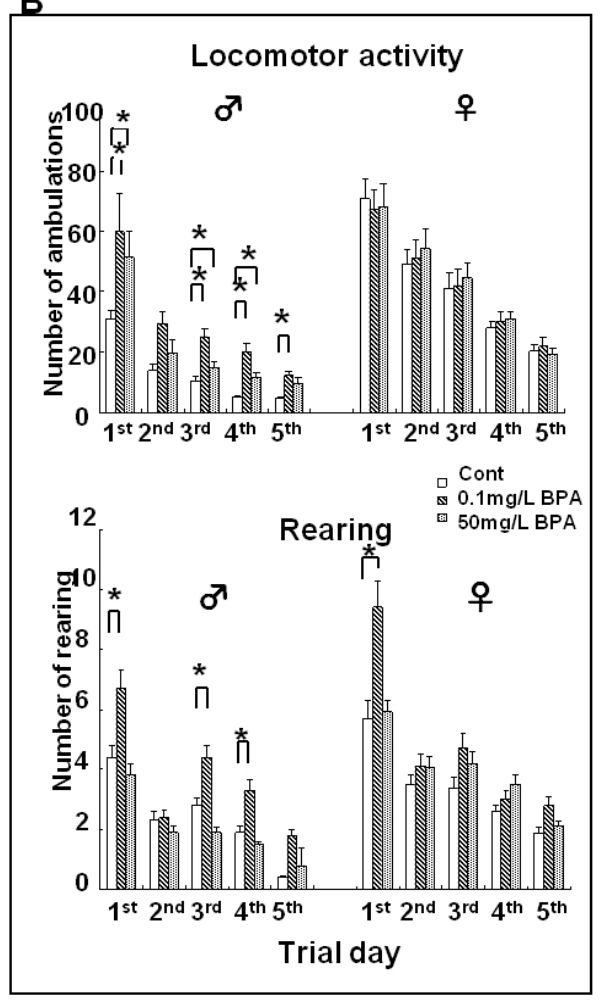

Fig. 6. Latency time in the Morris water maze test. 
Male pups of the low-dose BPA $(0.1 \mathrm{mg} / \mathrm{L})$ group showed more locomotor activity and more frequent rearing than control male pups, whereas those from the high-dose BPA group did not show differences in rearing activity, except a less marked but significant increase in locomotor activity. Female pups, in contrast, showed no change in either locomotor or rearing activity at either BPA dose (Fig 6).

The Morris water maze test was carried out at 10 weeks of age. The apparatus was a circular pool (diameter $=1.5 \mathrm{~m}$ ) of water maintained at a temperature of $25 \pm 1^{\circ} \mathrm{C}$. The pool was divided into 4 sectors (ie, N, S, E, and W) and a transparent resin goal platform, $10 \mathrm{~cm}$ in diameter, was placed approximately $1.5 \mathrm{~cm}$ below the water surface about halfway between the edge and the center of the pool in the $S$ sector. Each experimental animal performed 2 trials per day for 5 days, and the maximum time permitted for 1 trial was $120 \mathrm{~s}$. If the animal had not reached the goal by the end of the trial, it was led to the goal platform and left on it for $15 \mathrm{~s}$. The escape time of every trial was recorded manually. After every trial, any visible feces were removed from the pool (Fig 7).

Morris water maze

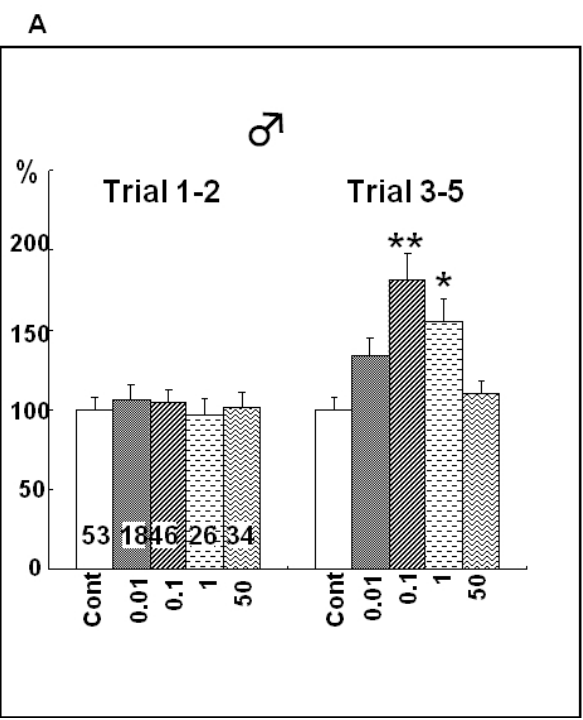

B

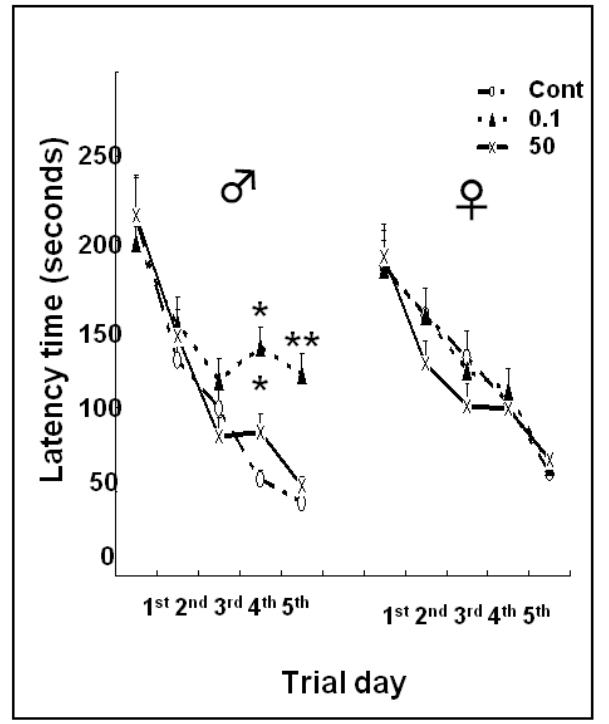

Fig. 7. Effect of $0.1 \mathrm{mg} / \mathrm{L}$ bisphenol A (BPA) on thyroid hormone receptor (TR)-a expression in the male hippocampus.

The results of the water maze test were similar to those of the open field test. Male offspring from the low-dose BPA group required about 2.2-fold more time to reach the goal compared to controls on days 4 and 5 of the trial. The effect of high-dose BPA treatment was less obvious than that of low-dose BPA treatment. Female offspring from both BPA-treated groups showed no impairment of spatial learning at all.

These behavioral outcomes paralleling the results of the quantitative determination of serum T4 levels suggest that perinatal BPA exposure disturbs normal thyroid function, 
consequently leading to irreversible neurological deficits. Why were the males predominantly affected by perinatal BPA exposure? What is the underlying mechanism? We performed further studies to address these critical questions and to unravel the mystery.

Firstly, to assess the thyroid hormone pathway, we investigated the expression of TR- $\alpha,-\beta$, $\mathrm{RC} 3$ /neurogranin, and SRC-1 in the developing hippocampus, a region deeply involved in cognition. The CA1 region of the hippocampus where memory is encoded, consolidated, and stored by synaptic plasticity plays a more crucial role for spatial learning (Huang YY 1995; Vara H 2003). TR-a was highly expressed in the CA1-2 region and dentate gyrus at day 7 after birth (Fig 8), while RC3/neurogranin showed high mRNA levels in the hippocampus from days 7 to 42 after birth. However, BPA treatment did not cause differences in TR-a or RC3/neurogranin levels compared to controls. TR- $\beta$ was not expressed in the hippocampus throughout the period tested.

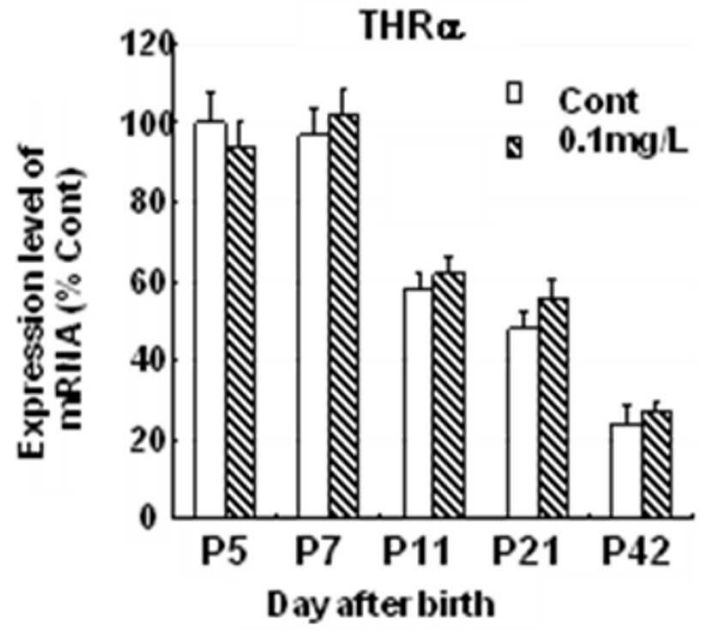

Fig. 8. Effect of $0.1 \mathrm{mg} / \mathrm{L}$ bisphenol A (BPA) on RC3/neurogranin expression in the male hippocampus.

Although no change was observed in the expressions of TR- $\alpha, \beta$, and the thyroid responsive gene RC3/neurogranin of BPA-treated male pups, SRC-1 levels were significantly upregulated in the CA1-2 region of the hippocampus by BPA treatment from days 5 to 7 after birth (Fig 9). SRC-1 is a member of the growing family of cellular proteins that act as "amplifiers" of transcription mediated by nuclear receptors upon ligand binding. Therefore, its expression is also regulated by the expression levels of nuclear receptors. Our findings indicate that perinatal BPA exposure at a very low level may influence thyroid function and, consequently, affects brain development only in male pups, while TR itself seems unlikely to be involved. Since SRC-1 is a common transcription cofactor for thyroid hormone as well as other steroid hormones, the involvement of gonadal hormones and their receptors should be taken into account. In this regard, a very clear gender difference of BPA disruption on thyroid function and behavior outcome would support, at least in part, this assumption. However, further investigation is needed. 


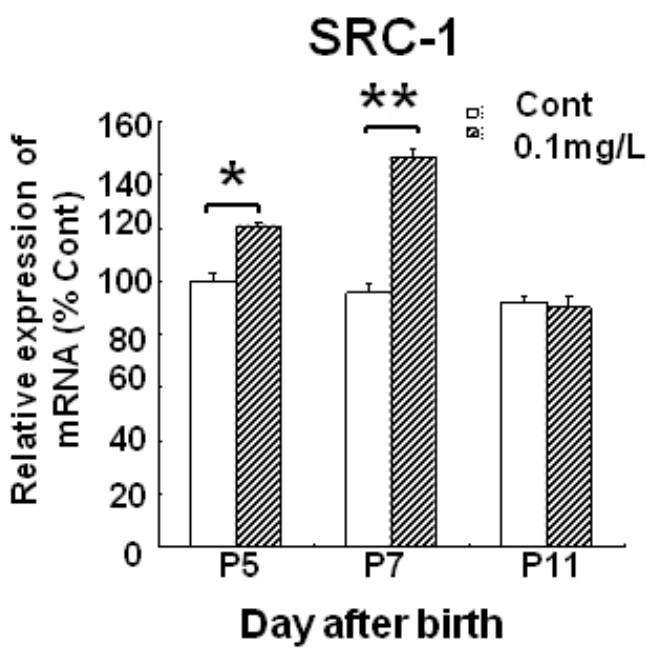

Fig. 9.

The results of our other study support the hypothesis that BPA disturbs brain development via the gonadal hormone pathway. Because there is a significant sexual difference for sweet taste in rats, ie, female rats prefer sweetness more than male rats, we treated maternal rats with $0.1 \mathrm{mg} / \mathrm{L} \mathrm{BPA}$ (supplied in the drinking water from gestational day 11 until day 21 after delivery). Then, the offspring were supplied with water containing $15 \%$ sucrose. We found that BPA-treated male rats liked sucrose more than control rats, while BPA-treated female rats showed less preference for sucrose than control rats. Sexual differentiation of sweet taste was weakened by BPA treatment (Xu X 2011). This finding further suggests involvement of the gonadal hormone pathway in BPA-mediated disruption.

Gonadal hormone receptors and TRs are members of the nuclear receptor superfamily that bind low-molecular-weight ligands (gonadal hormone and thyroid hormone, respectively). They transduce these signals in gene regulatory events. These receptors have a modular protein structure with high homology in the central DNA binding domain. It has been well documented that there is cross-talk between members of the nuclear receptor superfamily which can multiply the theoretically possible modes of gene regulation, leading to a greater and more flexible array of transcriptional responses to environmental changes (Vasudevan $\mathrm{N}$ 2002). BPA may influence thyroid function via the gonadal hormone pathway, consequently affecting sexual differentiation and impairing brain development modulated by the thyroid.

Convincing evidence showed widespread exposure to BPA in $95 \%$ of urine samples from people in the United States examined by the Centers for Disease Control and Prevention. Furthermore, BPA has recently been shown to be present in the serum during pregnancy as well as in fetal serum and full-term amniotic fluid, confirming its passage through the placenta. These findings translate into an increasing threat to public health. Because the neonatal period of rats is equivalent to the midgestation period in humans, the present study may provide a warning that BPA exposure to fetuses may lead to behavioral 
abnormalities and cognitive dysfunction in the hippocampus in humans, especially in case of boys. At present, there is no direct evidence linking the increasing number of children with ADHD and autism to large consumption of chemical compounds. Therefore, carefully controlled studies examining this association are urgently needed.

\section{References}

Ahmed OM, A. E.-T. S., Ahmed RG. (2010). "Effects of experimentally induced maternal hypothyroidism and hyperthyroidism on the development of rat offspring: I. The development of the thyroid hormones-neurotransmitters and adenosinergic system interactions." Int J Dev Neurosci. 28(6): 437-454.

Akaike, M., Kato, N. (1997). "Abnormal behavior, spatia learning impairment and neuropeptides caused by temporary neonatal hypothyroidism." Recent Res, Dev, Neuroendo.: 39-48.

Akaike, M., Kato, N., Ohno, H., Kobayashi, T. (1991). "Hyperactivity and spatial maze learning impairment of adult rats with temporary neonatal hypothyroidism." Neurotoxicol Teratol. 13(3): 317-322.

Bradley, D., Towle, HC., Young III, WS. (1992). "Spatial and temporal expression of a- and bthyroid hormone receptor mRNAs, including the b2-subtype, in the developing mammalian nervous system." J. Neurosci. 12(6): 2288-2302.

Carr R, B. F., Betancourt A, Bowers S, Gandy BS, Ryan P, Willard S. (2003). "Effect of neonatal rat bisphenol a exposure on performance in the Morris water maze." $J$ Toxicol Environ Health A. 66(21): 2077-2088.

Chess, S. (1977). "Follow-up report on autism in congenital rubella." J Autism Child Schizophr. 7(1): 69-81.

Colborn, T. (2004). "Neurodevelopment and endocrine disruption." Environ. Health Perspect. 112(9): 944-949.

Colvis CM, P. J., Goodman RH, Impey S, Dunn J, Mandel G, Champagne FA, Mayford M, Korzus E, Kumar A, Renthal W, Theobald DE, Nestler EJ. (2005). "Epigenetic mechanisms and gene networks in the nervous system." J Neurosci. 25(45): 1037910389.

Forrest D, H. E., Smeyne RJ, Everds N, Stewart CL, Wehner JM, Curran T. (1996). "Recessive resistance to thyroid hormone in mice lacking thyroid hormone receptor beta: evidence for tissue-specific modulation of receptor function." EMBO J. 15(12): 30063015.

Gauthier K, P. M., Harvey CB, Williams GR, Weiss RE, Refetoff S, Willott JF, Sundin V, Roux JP, Malaval L, Hara M, Samarut J, Chassande O. (2001). "Genetic analysis reveals different functions for the products of the thyroid hormone receptor alpha locus." Mol Cell Biol. 21(14): 4748-4760.

González-Burgos I, F.-V. A. (2008). "Serotonin/dopamine interaction in memory formation." Prog Brain Res. 172: 603-623.

Guadaño-Ferraz A, O. M., St Germain DL, Bernal J. (1997). "The type 2 iodothyronine deiodinase is expressed primarily in glial cells in the neonatal rat brain." Proc Natl Acad Sci U S A. 94(19): 10391-10396.

Huang YY, K. E., Varshavsky L, Brandon EP, Qi M, Idzerda RL, McKnight GS, Bourtchouladze R. (1995). "A genetic test of the effects of mutations in PKA on 
mossy fiber LTP and its relation to spatial and contextual learning." Cell 83(7): 12111222.

Jacobson JL, J. S. (1991). "Assessment of teratogenic effects on cognitive and behavioral development in infancy and childhood." NIDA Res Monogr. 114: 248-261.

Jacobson, S., Fein, GG., Jacobson, JL., Schwartz, PM., Dowler, JK. (1985). "The effect of intrauterine PCB exposure on visual recognition memory." Child Dev. 56(4): 853860.

Jeyakumar M, L. X., Erdjument-Bromage H, Tempst P, Bagchi MK. (2007). "Phosphorylation of thyroid hormone receptor-associated nuclear receptor corepressor holocomplex by the DNA-dependent protein kinase enhances its histone deacetylase activity." J Biol Chem. 282(13): 9312-9322.

Kato, N., Akaike, M., Masui, A., Naruse, H. (1992). Brain somatostatin in possible animal models of infantile autism., Elsevier Science Publishers.

Kato, N., Sundmark, VC., Van Middlesworth, L., Havlicek, V., Friesen, HG. (1982). "Immunoreactive somatostatin and beta-endorphin content in the brain of mature rats after neonatal exposure to propylthiouracil." Endocrinology 110(6): 1851-1855.

Kubo, K., Arai, O., Ogata, R., Omura, M., Hori, T., Aou, S. (2001). "Exposure to bisphenol A during the fetal and suckling periods disrupts sexual differentiation of the locus coeruleus and of behavior in the rat." Neurosci. Lett. 304(1-2): 73-76.

Lakshmy R, K. M., Das BC, Shah P, Ammini AC. (1999). "Effect of PTU treatment on histone acetylation pattern in the developing rat brain." Endocr Res. 25(11): 75-88.

Leonard JL, F. A., Yen PM, Chin WW, Stula M. (1994). "Differential expression of thyroid hormone receptor isoforms in neurons and astroglial cells." Endocrinology. 135(2): 548-555.

Lu EJ, B. W. (1977). "An electron microscopic study of the developing caudate nucleus in euthyroid and hypothyroid states." Anat Embryol (Berl). 150(3): 335-364.

Madeira MD, P.-B. M. (1993). "Reorganization of mossy fiber synapses in male and female hypothyroid rats: a stereological study." J Comp Neurol. 337(2): 334-352.

Manzano J, B. J., Morte B. (2007). "Influence of thyroid hormones on maturation of rat cerebellar astrocytes." Int J Dev Neurosci. 35(3): 171-179.

Mellström B, N. J., Santos A, Gonzalez AM, Bernal J. (1991). "Independent expression of the alpha and beta c-erbA genes in developing rat brain." Mol Endocrinol. 5(9): 13391350 .

Moriyama, K., Tagam, T., Akamizu, T., Usui, T., Saijo, M., Kanamoto, N., Hataya, Y., Shimatsu, A., Kuzuya, H., Nakao, K. (2002). "Thyroid hormone action is disrupted by bisphenol A as an antagonist." J. Clin. Endocrinol. Metab. 877(11): 5185-5190.

Oades, R. (2008). "Dopamine-serotonin interactions in attention-deficit hyperactivity disorder (ADHD)." Prog Brain Res. 172(543-565).

Porterfield, S. (2000). "Thyroidal dysfunction and environemntal chemicals: potential impact on brain development." Environ. Health Perspect. 108(suppl3): 433-438.

Rinaldi A, R. S., Agustín-Pavón C, Oliverio A, Mele A. (2010). "Distinct patterns of Fos immunoreactivity in striatum and hippocampus induced by different kinds of novelty in mice." Neurobiol Learn Mem. 94(3): 373-381. 
Sher ES, X. X., Adams PM, Craft CM, Stein SA. (1998). "The effects of thyroid hormone level and action in developing brain: are these targets for the actions of polychlorinated biphenyls and dioxins?" Toxicol Ind Health. 14(1-2): 121-158.

Siesser WB, C. S., McDonald MP. (2005). "Hyperactivity, impaired learning on a vigilance task, and a differential response to methylphenidate in the TRbetaPV knock-in mouse." Psychopharmacology (Berl). 181(4): 653-663.

Siesser WB, Z. J., Miller LR, Cheng SY, McDonald MP. (2006). "Transgenic mice expressing a human mutant beta1 thyroid receptor are hyperactive, impulsive, and inattentive." Genes Brain Behav. 5(3): 282-297.

Tousson E, I. W., Arafa N, Akela MA. (2011). "Monoamine concentrations changes in the PTU induced hypothyroid rat brain and the ameliorating role of folic acid." Hum Exp Toxicol. Apr.

Tsankova N, R. W., Kumar A, Nestler EJ. (2007). "Epigenetic regulation in psychiatric disorders." Nat Rev Neurosci. 8(5): 355-367.

Van Middlesworth, L., Norris, CH. (1980). "Audiogenic seizures and cochlear damage in rats after perinatal antithyroid treatment." Endocrinology 106(6): 1686-1690.

Vara H, M.-C. J., Colino A. (2003). "Age-dependent alterations of long-term synaptic plasticity in thyroid-deficient rats." Hippocampus. 13(7): 816-825.

Vasudevan N, O. S., Pfaff D. (2002). "Estrogen and thyroid hormone receptor interactions: physiological flexibility by molecular specificity." Physiol Rev. 82(4): 923-944.

Wallis K, S. M., van Hogerlinden M, Silberberg G, Fisahn A, Nordström K, Larsson L, Westerblad H, Morreale de Escobar G, Shupliakov O, Vennström B. (2008). "Locomotor deficiencies and aberrant development of subtype-specific GABAergic interneurons caused by an unliganded thyroid hormone receptor alpha1." J Neurosci. 28(8): 1904-1915.

Wong R, V. V., Ting YT, Kutler DI, Willingham MC, Weintraub BD, Cheng S. (1997). "Transgenic mice bearing a human mutant thyroid hormone beta 1 receptor manifest thyroid function anomalies, weight reduction, and hyperactivity." Mol Med. 3(5): 303-314.

Xu X, T. L., Himi T, Sadamatsu M, Tsutsumi S, Akaike M, Kato N. (2011). "Changed preference for sweet taste in adulthood induced by perinatal exposure to bisphenol A-A probable link to overweight and obesity." Neurotoxicol Teratol. June.

Zhang J, L. M. (2000). "The mechanism of action of thyroid hormones." Annu Rev Physiol. 62(439-466).

Zoeller, R., Bansal, R., Parris, C. (2005). "Bisphenol-A, an environmental contaminant that acts as a thyroid hormone receptor antagonist in vitro, increases serum thyroxine, and alters RC3/neurogranin expression in the developing rat brain." Endocrinology 146(2): 697-612. 


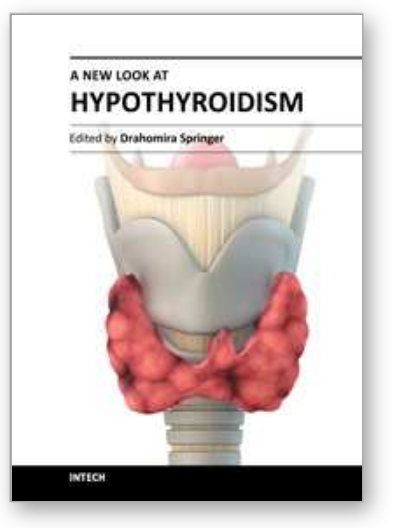

\author{
A New Look at Hypothyroidism \\ Edited by Dr. Drahomira Springer
}

ISBN 978-953-51-0020-1

Hard cover, 256 pages

Publisher InTech

Published online 17, February, 2012

Published in print edition February, 2012

Hypothyroidism is the most common thyroid disorder. It can cause a variety of changes in women's menstrual periods, reduce their chances of becoming pregnant, as well as affect both the course of pregnancy and the neuropsychological development of babies. During pregnancy there is a substantially increased need for thyroid hormones and a substantial risk that a previously unnoticed, subclinical or latent hypothyroidism will turn into overt hypothyroidism. The thyroid inflammation caused by the patient's own immune system may form autoimmune thyroiditis (Hashimoto's thyroiditis). Congenital hypothyroidism $(\mathrm{CH})$ occurs in approximately $1: 2,000$ to $1: 4,000$ newborns. Nearly all of the developed world countries currently practice newborn screening to detect and treat congenital hypothyroidism in the first weeks of life. "A New Look at Hypothyroidism" contains many important specifications and innovations for endocrine practice.

\title{
How to reference
}

In order to correctly reference this scholarly work, feel free to copy and paste the following:

Xiaobin Xu, Hirohiko Kanai, Masanori Ookubo, Satoru Suzuki, Nobumasa Kato and Miyuki Sadamatsu (2012). Consideration of Congenital Hypothyroidism as the Possible Cause of Autism, A New Look at Hypothyroidism, Dr. Drahomira Springer (Ed.), ISBN: 978-953-51-0020-1, InTech, Available from:

http://www.intechopen.com/books/a-new-look-at-hypothyroidism/consideration-of-congenital-hypothyroidismas-the-possible-cause-of-autism-

\section{INTECH}

open science | open minds

\section{InTech Europe}

University Campus STeP Ri

Slavka Krautzeka 83/A

51000 Rijeka, Croatia

Phone: +385 (51) 770447

Fax: +385 (51) 686166

www.intechopen.com

\section{InTech China}

Unit 405, Office Block, Hotel Equatorial Shanghai

No.65, Yan An Road (West), Shanghai, 200040, China

中国上海市延安西路65号上海国际贵都大饭店办公楼 405 单元

Phone: +86-21-62489820

Fax: $+86-21-62489821$ 
(C) 2012 The Author(s). Licensee IntechOpen. This is an open access article distributed under the terms of the Creative Commons Attribution 3.0 License, which permits unrestricted use, distribution, and reproduction in any medium, provided the original work is properly cited. 